\title{
IN MEMORIAM|
}

\section{La profesión jurídica*}

\section{Fernando Hinestrosa**}

Nuevamente el Señor Presidente del Instituto Colombiano de Derecho Procesal, Dr. Jairo Parra Quijano, me ha abrumado con su deferencia invitándome a abrir la reunión académica más significativa, que anualmente congrega a los estudiosos del derecho en nuestro país. Se dirá que, en virtud de esa generosidad, la intervención mía tiende a convertirse en punto fijo del orden del día. Van para él mis sentimientos de gratitud, a la vez que la reiteración de mi aprecio y admiración, por sus calidades intelectuales y sus virtudes cívicas, de las que dan testimonio el reconocimiento de su persona y su actividad por parte del foro nacional y los pares extranjeros, y la solidez y la prestancia bien ganada por el Instituto bajo su pujante dirección.

En este foro, en oportunidades anteriores me he referido al oficio del profesional del derecho, juez o abogado, como también a la formación del jurista; permítanme Uds. que hoy vuelva sobre esos tópicos, solo que con una visión más general, si que también más remitida al desempeño de aquel, a su realidad cotidiana y a su devenir, a su función y su misión en la sociedad de aquí y hoy, sin perder de vista la universalidad de muchos de los problemas y de las tendencias que nos aquejan y ocupan.

No creo ocioso traer a colación los conceptos de derecho, justicia, equidad, y la actividad de quienes han de elaborar aquel para la regulación de la conducta de los distintos miembros sociales y, al interpretarlo y aplicarlo, hacer efectivos

Conferencia de instalación del I Congreso Colombiano de Derecho Procesal, Cartagena de Indias, 27 de septiembre de 2000 .

Para citar el artículo: F. Hinestrosa, "La profesión jurídica", Revista de Derecho Privado, Universidad Externado de Colombia, n. ${ }^{\circ}$ 30, enero-junio de 20r6, 5-I3. DOI: http://dx.doi. org/I0.1860I/or 234366.n30.0 I

** Rector de la Universidad Externado de Colombia (I963-201 2), Colombia. La Revista de Derecho Privado presenta, a partir del número 24 , los trabajos referidos al derecho civil y romano de quien fuera su fundador y constante y decidido animador. La mayoría de los trabajos ya han sido publicados, pero el afán de facilitar su divulgación, en especial entre los estudiantes, nos lleva a volverlos a presentar, seguros no solo de su utilidad, sino también de su permanente actualidad. 
esos dictados y principios en la prevención y solución de los conflictos. ¿Cómo no recordar las tareas primordiales de cavere, scribere, agere, que ocuparon a los jurisconsultos romanos y siguen siendo el núcleo del quehacer del profesional del derecho y que, por lo mismo, le otorgan una posición singular en la sociedad, a tiempo que le exigen condiciones, calidades y talante correspondientes a la trascendencia de sus responsabilidades y que, a su turno, implican un proceso de formación calificada y devoción y fidelidad a ese destino?

Podría llegarse a pensar que en el mundo actual, con un alto grado de división del trabajo, de tecnología y de especialización, cada cual de los campos de actividad reservados al profesional del derecho demanda una preparación diferenciada a propósito, rasgos de personalidad y de carácter y una disposición específicos: la concepción y redacción de normas, el asesoramiento para la contratación o para el litigio, el patrocinio judicial, la guarda de la fe pública, en fin, el ejercicio de la jurisdicción. Como también habría de tenerse presente que dicho profesional se encuentra, por eso mismo, más próximo a la cosa pública y, por ello, ha de ser más sensible al interés común, más proclive al ejercicio de la política y a la conducción del Estado.

Sin incurrir en remembranzas nostálgicas, "dichosa edad, tiempos aquellos", ha de hacerse memoria de las épocas de formación de la República y de los primeros pasos firmes hacia su concepción democrática e igualitaria, en los intervalos de las guerras civiles del siglo pasado, en las que sobresale la figura del abogado estadista, para quien la organización del Estado y la eficiencia de la administración pública eran su ocupación primordial, y es ineludible cotejar la actitud y postura del abogado de antes, hasta avanzado el siglo xx, con la mentalidad y las aspiraciones del de hoy, de modo de palpar la diferencia, en la que mucho tienen que ver el desarrollo económico, la complejidad creciente de las relaciones intersubjetivas, el avance de otras profesiones y, sin duda, un cambio de los ideales, paradigmas y, por supuesto, de las exigencias de la vida cotidiana.

En una sociedad prevalecientemente agraria, con peso reducido del artesanado, e inclusive en una sociedad con industrialización incipiente, era natural que el abogado volcara sus anhelos y sus empeños a la función pública, la jurisdicción y el notariado, menesteres propios de su condición, pero también a la dirección política y administrativa del Estado. El ejercicio profesional independiente se reducía prácticamente a los juicios penales, cuyo trámite espectacular alentaba el renombre político, a los conflictos de tierras, aguas y familiares, a la redacción de testamentos y contratos, a las mortuorias, y a ejecuciones y lanzamientos. Todo lo cual, por lo demás, a la vez que exigía un bagaje humanístico y retórico básico, daba tiempo para el cultivo literario y artístico. El abogado era tenido, y por lo general con razón, por persona culta, y hasta pasaba por intelectual. De paso sea dicho, y con elogio, pese a las burlas ligeras y perversas a los gobernantes gramáticos, las constituciones y las leyes se redactaron en lenguaje elegante, asequible a todos y, cuanto lo primero, inteligible; y otro tanto cabe 
decir de las providencias judiciales, los alegatos, los contratos; todas esas piezas de ordinario breves y concisas, a despecho del tiempo de que se disponía para su redacción, o quizá por ello.

El abogado ocupaba, por esa pluralidad de motivos y circunstancias, una posición señera en las distintas comunidades, sobresaliente en el ámbito municipal, en donde aún mantiene su halo. El círculo profesional era reducido, y sin poderse sostener que fuera aristocrático, sí era objeto de estima y consideración especiales, por las calidades intelectuales, cívicas y éticas de sus integrantes, cuyo consejo se buscaba para muchos menesteres distintos del derecho, y se atendía en fuerza de su experiencia, prudencia y buen juicio. Puede afirmarse que se operaba una selección natural de los aspirantes a adelantar la carrera universitaria, mediante la comparación entre las aptitudes que exigía aquel arquetipo y la vocación del joven, y que el estudiante de derecho tenía por meta ser estadista o ser magistrado, o dicho más llanamente, desempeñarse en la dirección y la administración del Estado, o en las corporaciones públicas representativas, o fungir como juez, fiscal, procurador, e ir ascendiendo hasta llegar a la Corte; en otras palabras, su realización giraba en derredor del valor prestancia, del reconocimiento social. Su mente no daba cabida a la ostentación, tampoco podía soñar en la posibilidad de enriquecimiento con el trabajo profesional, y menos imaginar que la jurídica pudiera convertirse en profesión de alto riesgo. Se le identificaba de lejos por el hablar ampuloso, inherente a la exigencia de convencer, propia del oficio del abogado, es decir, por la retórica, y por su vestimenta formal, quizá el solo remanente de la toga y el birrete del ceremonial académico y de los estrados judiciales, que, sin embargo, no alcanzaba a mostrarlo petimetre.

Por lo demás, esa figura fue común a los distintos países del llamado mundo occidental, posiblemente más afectada o artificial en los de América Latina. La bibliografía que hoy se ocupa por doquier de examinar la transformación que se ha venido operando en el campo de la profesión jurídica resalta en el abogado de antaño esos ideales, valores, aspiraciones. Se señalan la sabiduría y el espíritu cívico como caracteres de aquel modelo, entendidos como una síntesis de formación humanística, esto es, filosófica y literaria, voluntad de servicio, ponderación, prudencia, y conocimiento y manejo ágil de máximas jurídicas y, por descontado, del lenguaje. A ese momento corresponde la disputa acerca de si el derecho era o es una ciencia, una técnica, un oficio o un arte, para privilegiar la orientación de que el ideal de abogado es el de una persona de buenos sentido y juicio, con criterio de equidad y una sensibilidad exquisita por el bien público, lo cual, a despecho de los artificios y juegos florales de la recitación de máximas latinas y párrafos enteros de textos doctrinarios farragosos, lo aproximaba a aquel paradigma clásico romano del ars boni et aequi.

De esa figura se fue pasando al abogado comprometido, a semejanza de la del 'intelectual comprometido', no menos artificiosa y vaga, y llegando al abogado 'técnico'. Aquel romanticismo, según las alineaciones, fue derivando hacia un 
ejercicio del derecho, ora político, ora técnico, adjetivos estos que han de ponerse entre comillas. En fuerza de una especie de ensoñación o embeleco estatista, dos generaciones atrás, se pretendió por gentes de "avanzada", en impulso que se ha prolongado inercialmente y por esfuerzos espasmódicos de los cultores de dicha tendencia, que la formación del jurista redujera, si no eliminara, el estudio de la normatividad en sí y en su devenir, para dar pábulo a la economía, la filosofía, la sociología, en una palabra, que la teología, ya marxista, ya cristiana, ocupara en la educación el lugar de la teoría general del derecho y de los principios de la hermenéutica y la dogmática de las distintas ramas de aquel. El profesional del derecho no debería, pues, ser, o aspirar a ser, un "jurisprudente”, sino un "ingeniero social", comprometido en el diseño de las instituciones, algo así como el "constructivismo" en el campo de las artes plásticas. Derribar, construir y reconstruir, pisándole los terrenos a la criminología, la estadística, la "ciencia" política, con actitud despectiva hacia el ejercicio rutinario de interpretar y aplicar la ley. Así, aquellas virtudes, aquella consideración de la tradición: las mores maiorum, el Volksgeist, o simplemente, el alma de la nación, resultaban contrarias al Diktat de la "Ciencia" y de la "Actualidad" y, por ende, debían ser inmoladas en el altar del cientifismo.

Pero sigamos el decurso de lo acontecido. A la segunda posguerra sucedió la Guerra Fría y a esta su "posguerra". La exaltación de la economía de mercado, la execración del "Welfare State", la privatización a ultranza pasaron a ocupar el lugar de los dogmas y lemas precedentes, auspiciadas por el anhelo natural de mejoramiento del nivel de vida de las clases emergentes. A grandes brochazos, el panel habría de incluir también la concurrencia del efecto demostrativo de la sociedad de consumo y, por ende, de la sustitución del "ser" por el "tener", o como se suele indicar con una paráfrasis shakespereana: "to have or not to have", en vez de "to be or not to be". La cuestión consiste hoy en poner de presente que la medida del valor humano es más patrimonial que personal, o simplemente, que la condición personal, como las obligaciones, ha de ser apreciada en dinero. ¿Será menester subrayar este hecho en un país humillado por Ia riqueza insolente del narcotráfico y la corrupción, e intimidado por el militarismo de todos los matices y raleas?

La sensación, el sabor que deja el examen atento de la situación del país, son amargos y es difícil no caer en la desesperanza. Las gentes no creen en el derecho, desconfían de las instituciones, ¿qué nos queda de democracia y a dónde irá a parar la libertad? El ciudadano se encuentra indefenso ante los matones, la policía anda comprometida en funciones distintas de las genuinas, y la fuerza pública no acierta a guardar un orden público resquebrajado, amén de que la ciudadanía no se siente comprometida con la suerte de la patria, a la que trata como a un ser ajeno a ella. La indisciplina social, la rebeldía dispersa, el egoísmo, en una palabra, la anomia, avanzan, corroen el alma nacional. Como en el poema En la niebla de Hermann Hesse, "nadie conoce al otro, cada cual está solo". Y 
las gentes se refugian en la insensibilidad, el desentendimiento, o simplemente allá desembocan, en razón de su impotencia y de la saturación de su capacidad de condolencia y repudio.

Sin embargo, la especie se las ingenia para sobrevivir; pese a que las naciones sí pueden desaparecer, ya no tanto por conquista o exterminación ajenas, cuanto por implosión, es decir, por canibalismo o antropofagia. Así, entre nosotros, el derecho subsiste, se proponen reformas constitucionales, se expiden leyes, decretos y resoluciones, abundantes, prolijas; de tarde en tarde se dictan sentencias judiciales; los abogados tienen mucho que hacer en todos los campos y ramas del ejercicio profesional; oleadas de jóvenes de variados orígenes acuden a las aulas ansiosos de hacerse abogados y crece la fertilidad universitaria: cada cabecera de circuito quiere tener $y$, en efecto la tiene, universidad o, en subsidio, una o varias sucursales de facultades de derecho de otras tantas llamadas universidades; a tiempo que la burocracia jurídica incrementa su número a lo largo y ancho del país. Por doquier se dice y repite que Colombia es un Estado social de derecho, y además se afirma orondamente que se está elaborando un nuevo derecho de factura judicial. El fetichismo jurídico, la creencia en el poder mágico de la norma o de la sentencia, no solo sigue imperando, sino que se expande, en sus dos dimensiones: cada viraje de esa índole es saludado como panacea, y apenas se exagera al decir que simultáneamente viene la denostación del nuevo régimen, porque expedida la norma o la providencia distintas, las cosas no cambiaron como por ensalmo.

Parejamente, esa impulsividad, que no da lugar a la decantación y la fascinación de una postmodernidad que no llega a ser contemporánea, acarrea incertidumbre, una inseguridad jurídica que tiene lugar al mismo tiempo que la personal y la política, catastróficas todas para el desarrollo del país y su imagen en el exterior. Bienvenidos los avances jurídicos, el cambio social, la lucha por la igualdad, reales y no meramente verbales, meditados y responsables, no convulsivos e intermitentes. La estabilidad jurídica no se puede confundir con el anquilosamiento, como tampoco es dable asimilar la improvisación al progreso. El profesional del derecho, y especialmente el legislador y el intérprete judicial, han de ser conscientes del costo social, político y económico de sus pronunciamientos.

$¿ Y$, a todas estas, cuál es el papel del profesional del derecho y cuál la responsabilidad que le cabe en el deterioro institucional que padecemos? No se trata de flagelarnos en público, universidades, profesores, magistrados, jueces, fiscales, notarios, legisladores, abogados. Sencillamente abramos los ojos, veamos qué ha ocurrido y que está ocurriendo. ¿Hasta dónde, por razones variadas, comenzando por una actitud de comodidad, conformismo, obsecuencia, o por terror, el profesional del derecho se ha encogido de hombros ante un estado de cosas perverso, e incluso se ha aprovechado individualmente de él? Percibiendo directamente las fallas de funcionamiento del Estado y de la sociedad, la protesta no 
va más allá del comentario anónimo acre en el corrillo. Nadie se le mide al riesgo de desagradar al poderoso o incomodar al superior, ni siquiera del de disentir. La legislación no es objeto de análisis crítico; mucho menos la jurisprudencia. Se recopilan y acumulan reverentemente pasajes de fallos, y se les esgrime con oportunismo. A la mora judicial se responde reprochando a la [acción de] tutela y creando inopinadamente nuevas plazas de jueces y magistrados, que dejan intactas las fallas de metodología en el trabajo. ¿Y a quién le duele la proliferación de escuelas de derecho y la producción masiva de abogados desprovistos de las calidades y herramientas indispensables para su desempeño profesional? El Estado, como es habitual, habrá de incorporarlos a su caudal burocrático, y la ciudadanía habrá de sufrir sus deficiencias de todo orden. Diera la impresión de que el ciudadano, sintiéndose no sólo indefenso, sino apabullado, prefiere convertirse en súbdito y disputar con sus congéneres el favor de los poderosos, entre quienes descuellan, por cierto, no solo los detentadores del poder público, sino también, y aún más, quienes representan intereses privados, y no nacionales. Todo lo cual tiene repercusiones adversas sobre la profesión jurídica en sus distintos estadios $\mathrm{y}$ ambientes.

Me dirijo a Uds., profesionales del derecho de todas las regiones del país, de todas las edades, con variada experiencia, que se desempeñan en los distintos oficios para los cuales habilita el título, con preocupación íntima, rayana en la angustia, aportando reflexiones ciertamente no amables y gratas, pero sí sinceras: antes que abogados somos ciudadanos, y en ambas condiciones tenemos posibilidades y responsabilidades mayores que las de otras gentes. Nuestra patria, nuestra profesión, se nos están desliendo; los ideales, principios, valores en los que hemos creído, que dan sustento a la propia existencia, se nos están esfumando, se han convertido en sombras, fantasmas, simulaciones. Y no podemos permanecer impávidos o indiferentes. Como abogados: legisladores, jueces, fiscales, consejeros, asesores, gestores, apoderados, profesores, hemos de reaccionar, individual y colectivamente; en nuestras manos está la posibilidad de volver por los fueros de la humanidad y la racionalidad en las relaciones entre los colombianos y, de ahí en adelante, la exigencia de rescatar la dignidad, la majestad y la efectividad del derecho y de la justicia. ¿Cómo? La respuesta es de las mayores sencillez y gravedad: ejerciendo la ciudadanía a plenitud, ejerciendo el derecho y administrando la justicia sinceramente, anteponiendo el bien público a cualquier interés particular, y teniendo presentes en toda oportunidad las exigencias fundamentales de la hombría de bien: el temple de carácter y la honestidad.

Ciertamente no me animan ni guían propósitos de retorno o vuelta a tiempos, concepciones y actitudes pretéritos o periclitados. Todos a una, hemos de rescatar los valores de la especie y de la patria, y con esas materias primas recrear el tejido social, la ética y el sentido del derecho. No son ellos, por cierto, "trabajos de Hércules"; cambios de actitudes, perseverancia de una conducta severa, estricta, vigilante de uno mismo y de los demás; solidaridad social, fe en 
la igualdad como valor y como medio, y búsqueda de ella, con sacrificio personal; voluntad y ética de servicio público, respeto al prójimo, cumplimiento de los deberes cívicos. Pedagogía cívica, social, jurídica.

El derecho es normatividad, pero no solo ella; es normas, pero también jurisprudencia, doctrina y usos y costumbres; en una palabra, es un código cultural de comportamiento. La normatividad y la jurisprudencia corren en lenguaje articulado y, por su propia función y por sentido político y estético, deben concebirse y redactarse en lenguaje claro, sencillo, inequívoco, con sindéresis y corrección gramatical.

El abogado: consultor, consejero, asistente judicial, debe ser honesto y leal con su cliente, pero antes y en mayor medida, debe serlo con la sociedad a que pertenece y se debe: su patria, el derecho, la justicia, el interés público. ¿Cómo no exigirle desempeño honesto y cumplimiento de esos deberes? ¿Hasta dónde se ha corrido el lindero moral para ver como ejercicio legítimo de derecho lo que simplemente es habilidosidad abogadesca, chicana, desplante, sin que haya autoridad gremial o estatal que la condene y ponga coto a ese permisivismo inmoral?

El juez, cualquiera que sea su posición y campo de acción, y por añadidura el fiscal, es un servidor público; su función es, como lo preceptúa la Constitución, la de administrar justicia pronta y cumplida; en forma sencilla, expedita. ¿Quién no recuerda el proceder de Sancho en el gobierno de la isla de Barataria, y no anhela la prevalencia del sentido común y de la equidad como dictados últimos del oficio de juzgador? ¿Hasta dónde la tardanza en la decisión y la liturgia del trámite contradicen la misión del derecho, suscitan y estimulan la violencia y favorecen el predominio del más rico, del más fuerte, del más astuto, en desmedro de las instituciones, la democracia y la libertad? ¿Acaso la justicia de las dictaduras para-estatales no resulta entonces más próxima al sentir de los súbditos, víctimas, a una, del abandono del Estado y de la arbitrariedad del déspota de turno?

¿Cuál es la realidad del acceso a la justicia y de la pregonada igualdad ante ella? ¿Qué hace el Estado, y lo que acá nos concierne más inmediatamente, qué hacemos los abogados en ambos sentidos? La verdad es que todo conspira contra los principios del derecho procesal y del derecho sustancial, y que una inmensa masa de ciudadanos yace en la más ominosa postración: no son ciudadanos o apenas lo son de clase inferior, sin que a nadie le importe esa afrenta.

¿Y qué decir de la pertinencia y la calidad de la legislación, la jurisprudencia y de la enseñanza del derecho? Para comenzar, es apremiante denunciar el dogmatismo, propio de la especie humana y del derecho, pero que por épocas se acentúa. La nuestra es una sociedad en extremo autoritaria. El autoritarismo dogmático campea desde el hogar. El argumento de autoridad formal priva sobre cualquier razonamiento disidente. El Magister dixit es lema universal: los padres ordenan, prohíben, sin dar explicación alguna, y castigan sin fórmula de juicio ni dosimetría; el maestro “dicta” clase, catequiza, no enseña ni orienta; el alumno repite, ora temeroso, ora oportunista. Todo propicia la cultura de la obediencia 
y proscribe la autonomía y la creatividad. Discrepar significa desacato. Las entidades administrativas interventoras y de vigilancia se pronuncian y proceden ex cathedra. El superior judicial, apenas funcional, se constituye de hecho en superior jerárquico, que no tolera disidencia. "La Corte dijo", es el argumento contundente, definitivo, en la argumentación judicial, sin reparar en la oportunidad, las circunstancias y la razón de aquel dicho; las providencias judiciales se cuentan, pero no se pesan. Legislación y jurisprudencia van por caminos separados; el método y los medios de legislar difícilmente permiten rastrear el estado de la cuestión, contar con auxilios estadísticos, sociológicos, antropológicos, investigaciones de campo, y excluyen la revisión de estilo. Cambios legislativos impulsivos, cuántas veces contradictorios, leyes exuberantes, innecesariamente extensas hasta la exageración, redactadas en lenguaje ininteligible, con fallas inaceptables gramaticales y de semántica.

¿Y qué hacer con el exhibicionismo judicial? En verdad no es nada edificante el espectáculo de magistrados de las altas cortes compitiendo en tiempo, espacio y vehemencia en la televisión y en la prensa, promulgando decisiones que no se han pronunciado aún, o rebatiendo las posiciones contrarias. No creo que demandar compostura y recato a propósito sea una posición anticuada o mojigata; la indiferencia, la resignación, cuando no la obsecuencia, han dado pie para que se generen hábitos malsanos, que desdicen de la compostura propia de la justicia y del buen gusto.

En fin, retornando a una reflexión recurrente, pienso que una manera de atacar muchos de estos males está en ir a una de sus raíces, es decir, a la formación del jurista. Para comenzar: el país no cuenta con un elenco docente para atender idóneamente setenta y más programas de derecho en los más dispares lugares de su geografía, como tampoco con un alumnado tan abundante, en condiciones de formarse para el desempeño calificado de una profesión que exige condiciones académicas, humanísticas, técnicas y éticas especiales. No se trata de restringir o negar las oportunidades de educación a estratos más amplios de la población, sino de procurar que la educación superior sea tal y de la calidad científica, técnica y ética que demanda el país, y que puede y debe impartir. Y para el caso del derecho, es urgente impedir que continúe su envilecimiento y el de la profesión jurídica.

Ahondando en estas reflexiones se encuentra la exigencia mayúscula de la formación ética del abogado: la deontología jurídica. Muchos son los que a dicho propósito optan por la vía simplista de imponer "clase de ética", es decir, por el facilismo de la prédica: 'sea honesto, sea correcto, no robe, no mienta, no calumnie, no falsifique'. Valga anotar a propósito que a nadie le han faltado en su día, en casa, en la escuela, la universidad, esas exhortaciones y admoniciones; y que el "back to basic" no es un anhelo apetecible ni benéfico. No es rasgándose las vestiduras y profiriendo anatemas ante la pérdida de los principios y los valores como se puede inculcar en la juventud sentido del honor y de la dignidad perso- 
nal, pundonor, solidaridad, gallardía, generosidad, nobleza. Aborrezco la moral del miedo. Creo sí en la exaltación de aquellas virtudes y rasgos de carácter por su propio mérito y, primordialmente, en el ejemplo de su práctica. Ese, para mí, el mensaje que los mayores hemos de enviar a la juventud.

Personalmente sé decir que amo entrañablemente la profesión jurídica en sus distintas expresiones; en ella me crié, a ella le debo lo que soy y de ella he recibido las mayores satisfacciones, como abogado, como magistrado, como profesor e investigador; siempre he repetido que tengo el administrar justicia coma el oficio más noble y ponderoso; emocionadamente evoco el empeño en que treinta y dos años atrás me comprometí con denuedo e idealismo por la recuperación de la dignidad y la majestad de la justicia. Cuanto más hayamos descendido en los últimos años, mayores han de ser nuestros esfuerzos de superación, no espasmódicos, sino constantes, perseverantes y universales. Y somos nosotros, todos los profesionales del derecho, quienes debemos encabezar y orientar esa cruzada, a sabiendas de su dificultad, de los obstáculos que se oponen, muchos de ellos inherentes al campo de acción y a la propia condición humana. Pero es nuestro deber, que hemos de cumplir con naturalidad, sin espíritu mesiánico, por patriotismo, por convicción, por amor propio, por tropismo. Confío en que la vida me alcance para ver esa nueva sociedad, reconstruida con nuestras propias manos sobre la base de los paradigmas de vigencia universal de los derechos fundamentales, de igualdad y de realidad del imperio de la rule of law. La patria digna y justa en la que soñamos. Sin temor de que, como el poeta surrealista francés, lleguemos a decir: "Tanto he soñado contigo, que hasta llegas a perder tu realidad". 